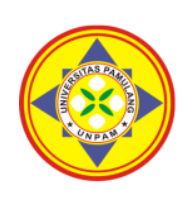

\title{
PENGARUH ANALISIS FUNDAMENTAL TERHADAP KEPUTUSAN INVESTOR DALAM BERINVESTASI DI BURSA EFEK INDONESIA (BEI)
}

\author{
1Ulil Amri, ${ }^{*}$ Digor Mufti \\ Universitas Muhammadiyah Sorong, Indonesia \\ *widyadigormufti27@gmail.com
}

\begin{abstract}
Abstrak
Penelitian ini bertujuan untuk mengetahui keeratan hubungan analisis fundamental terhadap keputusan berinvestasi di Bursa Efek Indonesia Khususnya di Galeri Investasi Bursa Efek Universitas Muhammadiyah Sorong, baik secara parsial maupun simultan. Jenis penelitian yang digunakan adalah pendekatan kuantitatif dengan metode deskriptif dan metode korelasi, dengan teknik pengambilan sampel menggunakan non probabilitas (Purposive Sampling). Tempat penelitian adalah Galeri Investasi Bursa Efek Indonesia Universitas Muhammadiyah Sorong. Sumber data didapat dari data sekunder berupa data investor Galeri Investasi Bursa Efek Indonesia Universitas Muhammadiyah Sorong dan data primer berupa kuisioner dengan responden yang merupakan investor dari Galeri Investtasi Bursa Efek Indonesia Universitas Muhammadiyah Sorong. Hasil penelitian menunjukan secara parsial variabel Kinerja perusahaan berhubungan positive dan signifikan terhadap keputusan berinvestasi 7,958. Pada variabel analisis persaingan usaha berhubungan positive dan signifikan terhadap keputusan berinvestasi 5,933. pada variabel analisis industri berhubungan positive dan signifikan terhadap keputusan berinvestasi 6,946. Pada variabel analisis ekonomi berhubungan positive dan signifikan terhadap keputusan berinvestasi 5,719. Pada variabel pasar makro-mikro berhubungan positive dan signifikan terhadap keputusan berinvestasi 8,880 . uji hipotesis secara simultan variabel kinerja perusahaan, analisis persaingan usaha, analisis industri, dan pasar makro-mikro berhubungan postif dan siginifikan terhadap keputusan berinvestasi sebesar hasil penelitian ini bermanfaat bagi investor sebelum memutuskan dan berinvestasi saham di Bursa Efek Indonesia.
\end{abstract}

Kata Kunci: BEI, Analisis Fundamental, Kinerja Perusahaan, Analisis Persaingan Usaha, Analisis Industri, Analisis Ekonomi, Keputusan Berinvestasi

\begin{abstract}
Purpose on this research is determine the close relationship of fundamental analysis on investment decisions on the Indonesia Stock Exchange, Especially at the Stock Exchange Investment Gallery of Muhammadiyah Sorong University, both partially and simultaneously. This type of research is a quantitative approach with descriptive methods and correlation methods, with sampling techniques using non-probability (Purposive Sampling). The place of this research at the Indonesia Stock Exchange Investment Gallery of Muhammadiyah Sorong University, which is located on the street no. 27 malaingkedi. Data source is obtained from primary data is lthe form of questionnaires with respondents who are investors from the Indonesia Stock Exchange Gallert of Muhammadiyah University Sorong and secondary data is the form of investor data on Indonesia Stock Exchange Investment Gallery of Muhammadiyah Sorong University. To solve the problem in this research used multiple linear regression analysis with the classic assumption test, partial test, simultaneous test, and the coefficient of determination. The results of partially test showed that company performance variable were positively and significantly related to investment decisions of 7,958, on business competition analysis variable is positively and significantly related to investment decisions of 5,933, on industry analysis variable are positively and significantly related to investment decisions 6,946, on economic analysis variables are positively and significantly related to investment decisions 5,719, on macro-micro market variables are positively and significantly related to the investment decision of 8,880. With simultaneously test showed that company performance, business competition analysis, industry analysis, and macro-micro markets are positively and significantly related to investment decisions. The results of this study are beneficial for investors before deciding and investing in shares on the Indonesia Stock Exchange
\end{abstract}

Keyword: Indonesia Stock Exchange, fundamental analysis, company performance, business competition analysis, industry analysis, economic analysis, macro-micro market, investment decision 


\section{PENDAHULUAN}

Keadaan pasar modal di Indonesia dalam tiga tahun belakang mangalami pertumbuhan, di tandai dengan adanya pergerakan IHSG cenderung menguat. Secara year on year IHSG menguat 9.93\%. Perkembangan yang sangat positif di pasar modal ini, juga berpengaruh pada minat masyarakat papua dalam memulai investasi di Bursa Efek Indonesia.

Analisis fundamental atau fundamental analysis adalah tekinik analisa yang memperhitungkan berbagai faktor, seperti kinerja perusahaan, analisis persaingan usaha, analisis industri, analisis ekonomi, dan pasar mikro-makro. Dari sini dapat diketauhi apakah perusahaan tersebut masih sehat atau tidak, dari pengecekan tersebut, investor dapat mengetahiu mana perusahaan yang dalam kondisi baik dan bisa dipilih untuk investasi.

Hipotesis dalam penelitian ini adalah H1 (ada prngaruh dan signifikan variabel kinerja perusahaan terhadap keputusan berinvestasi di Bursa Efek Indoneisa), H2 (ada pengaruh positif dan signifikan variabel analisis persaingan usaha terhadap keputusan berinvestasi di Bursa Efek Indoneisa,), H3 (ada pengaruh positif dan signifikan variabel analisis industry terhadap keputusan berinvestasi di Bursa Efek Indoneisa), H4 (ada pengaruh positif dan signifikan variabel analisis ekonomi terhadap keputusan berinvestasi di Bursa Efek Indoneisa), H5 (ada pengaruh positif dan signifikan variabel pasar makro-mikro terhadap keputusan berinvestasi di Bursa Efek Indoneisa), dan H6 (diantara variabel Kinerja Perusahaan, Analisis Persaingan Usaha, Analisis Industri, Analisis Ekonomi, dan Pasar Makro-Mikro, secara simultan berpengaruh paling dominan terhadap keputusan investor berinvestasi di Bursa Efek Indonesia (BEI)).

\section{TINJAUAN PUSTAKA}

1. Pasar modal

Sedangkan menurut Joel G. Siegel dan Jae K. Shim, pasar modal adalah pusat perdagangan utang janglka panjang dan saham perusahan. Adapun menurut R.J.Shook, pasar modal merupakan sebuah pasar tempat danadana modal, seperti ekuitas dan hutang, diperdagangkan. Produk (suart berharga) pasar,odal yang biasanya diperdagangkan dapat dibagi menjadi dua yakni surat berharga yang berbentuk kepemilikan da surat berharga yang bentuknya uang.

2. Saham

Saham adalah tanda bukti penyertaan kepemilikan modal/dana pada suatu perusahaan.

3. Common stock

Common stock (saham biasa)
adalah memiliki kelebihan
dibandingkan prefference stock
terutama diberi hak untuk ikut dalam
rapat umum pemegang saham (RUPS)
dan rapat umum luar biasa (RUPSLB)
yang otomatis memberikan wewenang
kepada pemegganya untuk ikut serta
dalam menentukan berbagai kebijakan
perusahaan. Commont Stock ini
memiliki beberapa jenis yaitu : blue chip-
stock (saham unggulan), growth stock,
defensive stock (saham-saham defnsif),
cyclical stock, seasonal stock, speculative
stock.

\section{METODE}

Metode penelitian ini adalah deskriptif dan korelasi. Definisi metode penelitian deskriptif menurut Sugiyono adalah penelitian yang bermaksud menggambarkan suatu keadaan atau nilai satu atau lebih variabel secara mandiri. Sedangkan definisi metode penelitian korelasi adalah penelitian yang bermaksud menggambarkan dan menguji hipotesis hubungan dua variabel atau lebih. Penelitian ini dilaksanakan mulai Juni Agustus 2019, bertempat di Bursa Efek Indonesia KP. Papua dan Papua Barat yang beralamat di Kompleks Perkantoran Adipura No.3 (Sebelah Daihatsu Polimak) Jayapura, Papua.

Populasi pada penelitian ini yaitu Populasi dalam penelitian ini ialah seluruh investor yang terdaftar di Galeri Investasi 
Universitas Muhammadiyah Sorong yang berjumlah 174 investor.. Dan sampel pada penelitian ini yait adalah sebagian dari populasi itu (Sugiyono, 2013: 389). Sampel pada penelitian ini adalah 92 investor yang terdaftar di Galeri Investasi Universitas Muhammadiyah Sorong

Sampel pada penelitian didapatkan dari teknik pengambilan sampel berupa nonprobability sampling yaitu purposive sampling dengan kriteria yaitu laporan keuangan diterbitkan setiap periode dan laporan keuangan dapat dianalisis dengan rasio keuangan.

Jenis data yang digunakan dalam penelitian adalah data kuantitatif. Sedangkan sumber data yang digunakan dalam penelitian ini adalah data primer dan sekunder yang meliputi Data primer yang digunakan peneliti ialah, kuisioner yang di bagikan ke responden baik dalam bentuk online (Google Form), dan Offline (Kuisioner Fisik). Data sekunder yang digunakan oleh peneliti ialah, data semua investor yang telah terdaftar di Galeri Investasi BEI Universitas Muhammadiyah Sorong.

Variabel pada penelitian ini terdiri dari variabel independen dan variabel dependen. Variabel independen pada penelitian ini yaitu Kinerja Perusahaan, Analisis Persaingan Usaha, Analisis Industri, Analisis Ekonomi, dan Pasar Makro-Mikro, sedangkan variabel dependen pada penelitian ini yaitu keputusan investor dalam berinvestasi di Bursa Efek Indonesia.

Metode analisis data pada penelitian ini terdiri atas Analisis Regresi Linear Berganda, Uji Prasyarat Analisis Regresi Linear Berganda (Uji Asumsi Klasik), dan Uji Hipotesis (Uji Parsial dan Uji Simultan).

\section{HASIL DAN PEMBAHASAN}

Berdasarkan hasil penelitian yang telah diuraikan sebelumnya menunjukkan bahwa terdapat pengaruh positif dan signifikan. Berikut ini dipaparkan penjelasan atas jawaban dari hipotesis penelitian. a. Pengaruh Kinerja Perusahaan Terhadap Keputusan Berinvestasi

Berdasarkan hasil penelitian bahwa pengaruh analisi persaingan usaha terhadap keputusan berinvestasi sebesar 0,558 dengan standar eror 0,050 dan pengaruhnya signifikan terhadap keputusan berinvestasi dengan nila $\mathrm{t}$ hitung 7,958 lebih besar dibandingkan dengan ttabel 1.66277, namun signifikan aktivitas lebih kecil dari tingkat kesalahan 5\%, atau 0,000 < 0,05 maka artinya terdapat pengaruh langsung antara kinerja perusahaan dengan keputusan berinvestasi. Maka H1 diterima dan H0 ditolak. Penelitian ini sejalan dengan penelitian Rifatin Cholidia (2017) yang menyatakan bahwa Kinerja Perusahaan berpengaruh positif terhadap keputusan berinvestasi.

b. Pengaruh Analisis Persaingan Usaha Terhadap Keputusan Berinvestasi

Berdasarkan hasil penelitian bahwa pengaruh analisis persaingan usaha terhadap keputusan berinvestasi sebesar 0,499 dengan standar eror 0,084 dan pengaruhnya signifikan terhadap keputusan berinvestasi dengan nila $t$ hitung 5,933 lebih besar dibandingkan dengan ttabel 1.66277, namun signifikan aktivitas lebih kecil dari tingkat kesalahan $5 \%$, atau $0,000<0,05$ artinya terdapat pengaruh langsung antara analisis persaingan usaha dengan keputusan berinvestasi. Maka H1 diterima dan H0 ditolak. Penelitian ini sejalan dengan penelitian Rifatin Cholidia (2017) yang menyatakan bahwa Analisis Persaingan Usaha berpengaruh positif terhadap keputusan berinvestasi.

c. Pengaruh Analisis Industri Terhadap Keputusan Berinvestasi

Berdasarkan hasil penelitian bahwa pengaruh analisis industri terhadap keputusan berinvestasi sebesar 0,659 dengan standar eror 0,095 dan pengaruhnya signifikan terhadap keputusan berinvestasi dengan nila $\mathrm{t}$ hitung 6,946 lebih besar dibandingkan dengan t-tabel 1.66277, namun signifikan aktivitas lebih kecil dari tingkat 
kesalahan 5\%, atau 0,000 < 0,05 maka artinya terdapat pengaruh langsung antara analisis industri dengan keputusan berinvestasi. Maka H1 diterima dan H0 ditolak Penelitian ini sejalan dengan penellitian Zarah Puspitaningtyas (2013) yang menyatakan bahwa Analisis Industri berpengaruh positif terhadap keputusan berinvestasi.

d. Pengaruh Analisis Ekonomi Terhadap Keputusan Berinvestasi

Berdasarkan hasil penelitian bahwa pengaruh analisis ekonomi terhadap keputusan berinvestasi sebesar 0,493 dengan standar eror 0,086 dan pengaruhnya signifikan terhadap keputusan berinvestasi dengan nila $t$ hitung 5,719 lebih besar dibandingkan dengan t-tabel 1.66277, namun signifikan aktivitas lebih kecil dari tingkat kesalahan 5\%, atau 0,000 < 0,05 artinya terdapat pengaruh langsung antara analisis ekonomi dengan keputusan berinvestasi. Maka $\mathrm{H} 1$ diterima dan $\mathrm{H} 0$ ditolak. 84 Penelitian ini sejalan dengan penelitian Zarah Puspitaningtyas (2013)yang menyatakan bahwa Analisis Ekonomi berpengaruh positif terhadap keputusan berinvestasi.

e. Pengaruh Pasar Makro-Mikro Terhadap Keputusan Berinvestasi

Berdasarkan hasil penelitian bahwa pengaruh pasar makromikro terhadap keputusan berinvestasi sebesar 0,732 dengan standar eror 0,082 dan pengaruhnya signifikan terhadap keputusan berinvestasi dengan nila $t$ hitung 8,880 lebih besar dibandingkan dengan t-tabel 1.66277, namun signifikan aktivitas lebih kecil dari tingkat kesalahan 5\%, atau 0,000 < 0,05 maka Ha diterima artinya terdapat pengaruh langsung antara pasar makro-mikro dengan keputusan berinvestasi. Maka H1 diterima dan H0 ditolak. Penelitian ini sejalan dengan penellitian Rifatin Cholidia (2017) yang menyatakan bahwa Kinerja Perusahaan berpengaruh positif terhadap keputusan berinvestasi. Penelitian ini sejalan dengan penellitian
Rifatin Cholidia (2017) yang menyatakan bahwa Pasar Makro-Mikro berpengaruh positif terhadap keputusan berinvestasi.

f. Pengaruh Kineja Perusahaan, Analisis Persaingan Usaha

Berdasarkan hasil penelitian maka diketahui bahwa nilai Ftabel sebesar 2,13 karena nilai Fhitung 24,885 lebih besar dari nilai Ftabel 2,13 85 maka dapat ditarik kesimpulan bahwa variabel bebas X1, X2, X3, X4, X5 (Secara simultan) berpengaruh terhadap variabel terikat (Y). diketahui nilai Sig. Sebesar 0,000. Karena nilai Sig 0,000 < 0,05 maka Ha diterima dan Ho Ditolak sesuai dengan dasar pengambilan keputusan dalam uji F maka dapat disimpulkan pula bahwa kinerja perusahaan (X1), analisi persaingan usaha $(\mathrm{X} 2)$, analisis industri (X3), analisis ekonomi (X4), pasar makromikro (X5) (secara simultan) berpengaruh terhadap keputusan berinvestasi $(\mathrm{Y})$. Maka $\mathrm{H} 1$ diterima dan $\mathrm{H} 0$ ditolak. Dan varibel independen $(X)$ yang paling berpengaruh terhadap variabel dependen (Y) ialah variabel pasar makro-mikro X5 dimana nilainya adalah 0,386 .

\section{PENUTUP \\ Kesimpulan}

Berdasarkan hasil penelitian dan pembahasan skripsi yang telah dilakukan dapat ditarik kesimpulan :

1. Penelitian ini membuktikan bahwa variabel KInerja Perusahaan memiliki pengaruh positif dan signifikan terhadap keputusan investor dalam berinvestasi di Bursa Efek Indonesia (BEI), sehingga hipotesis yang diajukan adalah H01 ditolak dan $\mathrm{H} 11$ diterima.

2. Penelitian ini membuktikan bahwa variabel Analisis Persaingan Usaha memiliki pengaruh positif dan signifikan terhadap terhadap keputusan investor dalam berinvestasi di Bursa Efek Indonesia (BEI), sehingga hipotesis yang diajukan adalah $\mathrm{H} 02$ ditolak dan $\mathrm{H} 12$ diterima.

3. Penelitian ini membuktikan bahwa variabel Analisis Industri memiliki 
pengaruh Positiv dan signifikan terhadap terhadap keputusan investor dalam berinvestasi di Bursa Efek Indonesia (BEI), sehingga hipotesis yang diajukan adalah $\mathrm{H} 03$ ditolak dan $\mathrm{H} 13$ diterima.

4. Penelitian ini membuktikan bahwa variabel Analisis Ekonomi memiliki pengaruh positif dan signifikan terhadap terhadap keputusan investor dalam berinvestasi di Bursa Efek Indonesia (BEI), sehingga hipotesis yang diajukan adalah $\mathrm{H} 04$ ditolak dan $\mathrm{H} 14$ diterima. Penelitian ini membuktikan bahwa variabel Pasar Makro-Mikro memiliki pengaruh positif dan signifikan terhadap terhadap keputusan investor dalam berinvestasi di Bursa Efek Indonesia (BEI), sehingga hipotesis yang diajukan adalah H05 ditolak dan H15 diterima.

6. Penelitian ini membuktikan bahwa variabel Kinerja Perusahaan, Analisis Persaingan Usaha, Analisis Industri, Analisis Ekonomi, Pasar Makro-Mikro secara simultan memiliki pengaruh positif dan signifikan terhadap terhadap keputusan investor dalam berinvestasi di Bursa Efek Indonesia (BEI). Sehingga hipotesis yang diajukan adalah H06 ditolak dan H16 diterima.

\section{Saran}

Adapun saran dari penulis yaitu Bagi peneliti agar lebih memahami cara analisis fundamental dan teknikal untuk berinvestasi saham di Bursa Efek Indonesia.

\section{DAFTAR PUSTAKA}

Abdalloh Irwan, Pasar Modal Syariah, Kompas Gramedia, Jakarta, 2018.

Aksara Bryan, Warren Buffet, Genesis Learning, Yogyakarta, 2017.

Anwar, Z., Kahar, M. S., Rawi, R. D. P., Nurjannah, N., Suaib, H., \& Rosalina, F. (2020). Development of Interactive Video Based Powerpoint Media In Mathematics Learning. Journal of Educational Science and Technology (EST), 6(2), 167-177.
Budiman Raymond, Rahasia Analisis Fundamnetal Saham, Kompas Gramedia, Jakarta, 2018.

D.Hadad Muliaman, OJK Way, Kompas Gramedia, Jakrta, 2017.

Fahmi Irfan, Manajemen Keuangan Perusahaan Dan Pasar Modal, Mitra Wacana Media,Jakarta, 2014.

Filbert Ryan \& Prasetya William, Investasi Saham Ala Fundamentalis Dunia, Kompas Gramedia, Jakarta, 2017.

Filbert Ryan, Trading Vs Investing, Kompas Gramedia, Jakarta, 2016.

Halim Abdul, Manajemen Bisnis, Mitra Wacana Media, Jakarta, 2015.

Hanadelansa, H., \& Rawi, R. D. P. (2019). Analisis Audit Operasional Atas Pemberian Kredit Pemilikan Rumah Pada Pt Bank Rakyat Indonesia (Persero) Tbk Kantor Cabang Panakukkang Di Kota Makassar. SENTRALISASI, 8(1), 3342.

Haque, M. G., Nurjaya, N., Affandi, A., Erlangga, H., \& Sunarsi, D. (2021). Micro Financial Sharia Non-bank Strategic Analysis: a Study at BMT Beringharjo, Yogyakarta. Budapest International Research and Critics Institute (BIRCI-Journal): Humanities and Social Sciences, 4(2), 1677-1686.

Hogan Nicky, Yuk Nabung Saham, Kompas Gramedia, Jakarta, 2018.

Mulyadi Bambang, Rules Of Investment, Kompas Gramedia, Jakarta, 2016.

Nasarudin M. Irsan, Surya Indra, Yustiavana Ivan, Nefi Arman, Adiwarman, Aspek Hukum Pasar Modal Indonesia, Kencana Pranad Media, Jakarta, 2014.

Noryani, Y. B. G., Sari, W. I., Rosini, I., Munadjat, B., Sunarsi, D., \& Mahnun Mas' adi, G. (2020). Did ISO 45001, ISO 22000, ISO 14001 and ISO 9001 Influence Financial Performance? Evidence from Indonesian Industries. PalArch's Journal of Archaeology of Egypt/Egyptology, 17(7), 6930-6950.

Pujiati, H., Sunarsi, D., Affandi, A., \& Anggraeni, N. (2021). Effect of ISO 
9001: 2015 Quality Management Implementation in Education on School Performance. Journal of Contemporary Issues in Business and Government, 27(1), 1848-1855.

Sawatiri Dyah, Ekonomi Mikro, Graha Ilmi, Yogyakarta, 2014.

Sinaga Benni, Rahasia Gelap DI Bursa Saham, Gerrmedia Pressindo, Bekasi, 2013. www.idx.co,id

Sugiyono, Metode Penelitian Bisnis, Alfabeta, Bandung, 2017.
Sujarweni V.Wiratna, Analisis Laporan Keuangan, Pustaka Baru Press, Yogyakarta, 2017.

Sukirno Sadono, Makroekonomi, PT Raja Grafindo Persada, Jakarta, 2015.

Suliyanto, Metode Penelitian Bisnis, Andi Offset, Yogyakarta, 2018.

Tsvetanov Georgi, Visual Finance, Kompas Gramedia, Jakarta, 2017.

Widarjono Agus, Stastitka Terapan Dengan Excel \& SPSS, UPP STIM TKPN, Yogyakarta, 2015. 